\title{
Acoustic tag retention rate varies between juvenile green and hawksbill sea turtles
}

\author{
Brian J. Smith ${ }^{*} \mathbb{0}$, Thomas H. Selby ${ }^{1}$, Michael S. Cherkiss², Andrew G. Crowder ${ }^{1}$, Zandy Hillis-Starr ${ }^{3}$, \\ Clayton G. Pollock ${ }^{3}$ and Kristen M. Hart ${ }^{2}$
}

\begin{abstract}
Background: Biotelemetry has become a key tool for studying marine animals in the last decade, and a wide range of electronic tags are now available for answering a range of research questions. However, comparatively, less attention has been given to attachment methods for these tags and the implications of tag retention on study design, especially when designing a comparative study looking at multiple species. Here, we reported our findings on acoustic tag retention rates for juveniles of two species of marine turtle: the green sea turtle (Chelonia mydas) and the hawksbill sea turtle (Eretmochelys imbricata). We captured both species twice annually (spring and fall) from 2012 through 2017, as part of a capture-mark-recapture study at Buck Island Reef National Monument, St. Croix, U.S. Virgin Islands. We assessed tag retention rates using physical recaptures of turtles previously outfitted with an acoustic tag.

Results: We deployed 72 acoustic tags on 60 juvenile greens and 37 acoustic tags on 29 hawksbills. We estimated the half-life for tags on greens to be 150 days ( $95 \%$ Cl 117-188 days), whereas the half-life for tags on hawksbills was 1077 days (95\% Cl 870-2118 days), a marked difference. We observed that tag attachment holes, drilled into the posterior marginal scutes, migrated laterally towards the outer edge of the marginals in both species. Green turtles tended to exhibit tear-outs, as their attachment holes wore and/or tags grew near the edge of their scutes, whereas hawksbills tended to maintain the structure of these holes and did not exhibit these tear-outs.

Conclusions: We conclude that hawksbills can be tagged with long-battery-life acoustic tags for long-term studies of habitat use and movement patterns, whereas greens are likely to shed their tags in the 1st year, making long-term studies difficult. This study is the first clear evidence that tagging protocols should vary between species of hardshelled turtles. Furthermore, shed tags on the seafloor continue to be detected by acoustic receivers, creating a challenge in data filtering before analysis. We encourage future research into an efficient method for filtering these data points prior to analysis.
\end{abstract}

Keywords: Passive acoustic telemetry, Marine turtles, Chelonia mydas, Eretmochelys imbricata, Study design

\section{Background}

Biotelemetry and biologging have been increasingly used in the last decade to study marine animals $[1,2]$. A variety of electronic tags are now available to record information on an individual's location, depth, physiology, or the environment it experiences [2]. The value of these tags

\footnotetext{
*Correspondence: bjsmith@contractor.usgs.gov

${ }^{1}$ Cherokee Nation Technologies, Contracted to the U.S. Geological Survey, Davie, FL 33314, USA

Full list of author information is available at the end of the article
}

for both basic ecological research and conservation and management is immense [3-5]. However, comparatively few studies have addressed the importance of tag attachment methods (but see [6, 7]). One major consideration when using tracking technology of any kind is how long tags will remain attached to an individual often expressed as the proportion of tags still attached after a given time, i.e., tag retention rate. Understanding tag retention rates is critical for designing a study that yields informative data, is cost effective, and minimizes any adverse effects 
on a tagged individual $[8,9]$. For instance, a researcher may be inclined to use a heavier, more expensive tag with a longer battery life, but if the retention rate is low, they will at best have wasted money and-worse-failed to collect adequate data to answer their research question. Retention rates are especially relevant when designing a comparative study for multiple species. Differences in tag retention rates between the species can make certain study designs impractical depending on the timescale.

Sea turtles have been studied with biotelemetry tags since the 1980s [10], and this research has produced important insights about their spatial ecology. With increasing anthropogenic threats to marine turtles worldwide, these findings have provided information on the efficacy of management decisions aimed at conserving remaining populations $[11,12]$. Recent advances in marine tracking technology have greatly expanded the amount and accuracy of location data recorded as well as environmental information associated with those locations. A range of biotelemetry tools have been used to study sea turtles, including radio transmitters, Argos satellite tags, GPS tags, acceleration data loggers, and acoustic transmitters [10, 13-15].

Acoustic telemetry can provide continuous, fine-scale location data for numerous individuals over extended periods of time (i.e., years) [2, 16]. Acoustic tracking can be active, where researchers follow a tagged animal with a directional hydrophone, or passive, where an array of fixed, omnidirectional receivers record tag transmissions. Large, collaborative networks of passive acoustic receivers are now increasingly popular around the world [17]. Passive acoustic technology is particularly well-suited for post-oceanic juvenile sea turtles, including greens (Chelonia mydas) and hawksbills (Eretmochelys imbricata). Like other sea turtles, greens and hawksbills exhibit ontogenetic shifts over long lifespans, wherein they utilize both oceanic and coastal environments [18]. After spending a variable number of years foraging at or near the surface in drifting oceanic weed lines during the 'lost years', juvenile greens and hawksbills actively recruit to neritic habitats, where they typically remain resident until sexual maturation $[18,19]$. The relatively shallow depth profile of these foraging habitats and limited home range of individuals makes favorable conditions for passive acoustic receiver arrays [16]. However, as with any technology, there are drawbacks and challenges that need to be fully understood before utilizing fixed passive telemetry to study juvenile green and hawksbill spatial ecology.

Few studies have utilized passive acoustic arrays to investigate either juvenile green or hawksbill spatial ecology [20-22]. Other studies have targeted adults or utilized other tracking techniques, and no research has specifically investigated acoustic tag retention rates for those species. Here, we outlined and evaluated Vemco V16 and V13 acoustic tag retention rates for juvenile green and hawksbill sea turtles tagged concurrently in a coastal Caribbean environment. Although tag retention was not the focus of the original study, our sample sizes and ample recapture rates provided sufficient information to quantify tag retention rates for these species.

\section{Methods}

We began capturing and tagging juvenile green and hawksbill sea turtles at Buck Island Reef National Monument (BIRNM) in the spring of 2012 as part of a capture-markrecapture study. BIRNM is a no-take marine protected area $2.4 \mathrm{~km}$ northeast of the island of St. Croix, U.S. Virgin Islands, that encompasses $73.4 \mathrm{~km}^{2}$ and is managed by the National Park Service (NPS). We partnered with NPS to deploy a small passive acoustic receiver array to investigate the movement and residency patterns of these turtles. In September 2011, six Vemco VR2W receivers (Vemco Amirix Systems, NS, Canada) were installed, and by 2016, the array had grown to a maximum of 141 receivers through collaborations with other academic, federal, and local researchers interested in a variety of species.

We conducted tagging trips for 8-10 days biannually (spring and fall). Here, we analyzed data from fieldwork through the fall of 2017. To capture individuals, two teams of three snorkelers swam designated transects and pursued any observed greens or hawksbills from the surface until they settled on the sea floor. One team member would then free dive to the bottom and grasp the turtle firmly by the carapace at the nuchal and anterior marginal scutes before slowly ascending with the turtle's head pointed towards the surface. We recorded morphometric measurements, including curved carapace length to the tip of the posterior marginal scute (CCL-t, in $\mathrm{cm}$ ) and mass $(\mathrm{kg})$. We then tagged individuals with either Vemco V16-4L $(16 \times 88 \mathrm{~mm}, 24 \mathrm{~g}$ in the air, $69 \mathrm{kHz}, 152 \mathrm{~dB}$, with $30-90 \mathrm{~s}$ delay interval) or V13-1L $(13 \times 36 \mathrm{~mm}, 11 \mathrm{~g}$ in the air, $60-84 \mathrm{kHz}, 147 \mathrm{~dB}$, with $30-90 \mathrm{~s}$ delay interval) acoustic tags, depending on the individual's size. We sought to deploy tags with as long a battery life as possible to provide long-term (i.e., years) detection profiles, as long as no tag exceeded $2 \%$ of the individual's body weight. Post hoc analysis revealed no tag exceeded $0.8 \%$ of an individual's body weight in the air.

We attached acoustic tags to the flattest section of the posterior marginal scutes (Fig. 1). The tagging area was prepared by hand sanding off any epibiotic growth with 80 grit sand paper under a steady stream of sea water. We placed the tag body in the slight grove between the upward flare of the outer marginals and the rest of the carapace. The area was then dried and cleaned with 91\% isopropyl alcohol, and a new $8 \mathrm{~mm}$ standard drill bit was cleaned 
with 91\% isopropyl alcohol. We used the clean bit to drill two holes into the marginal scutes parallel to each other, where the front (transmitting end) of the tag would sit and two more holes were the back of the tag would sit, for a total of four holes. In this case, the most lateral holes were typically $5-10 \mathrm{~mm}$ from the edge of the scute, and this distance was consistent for the two species. Acoustic tags from the V13 family with plastic end cap received
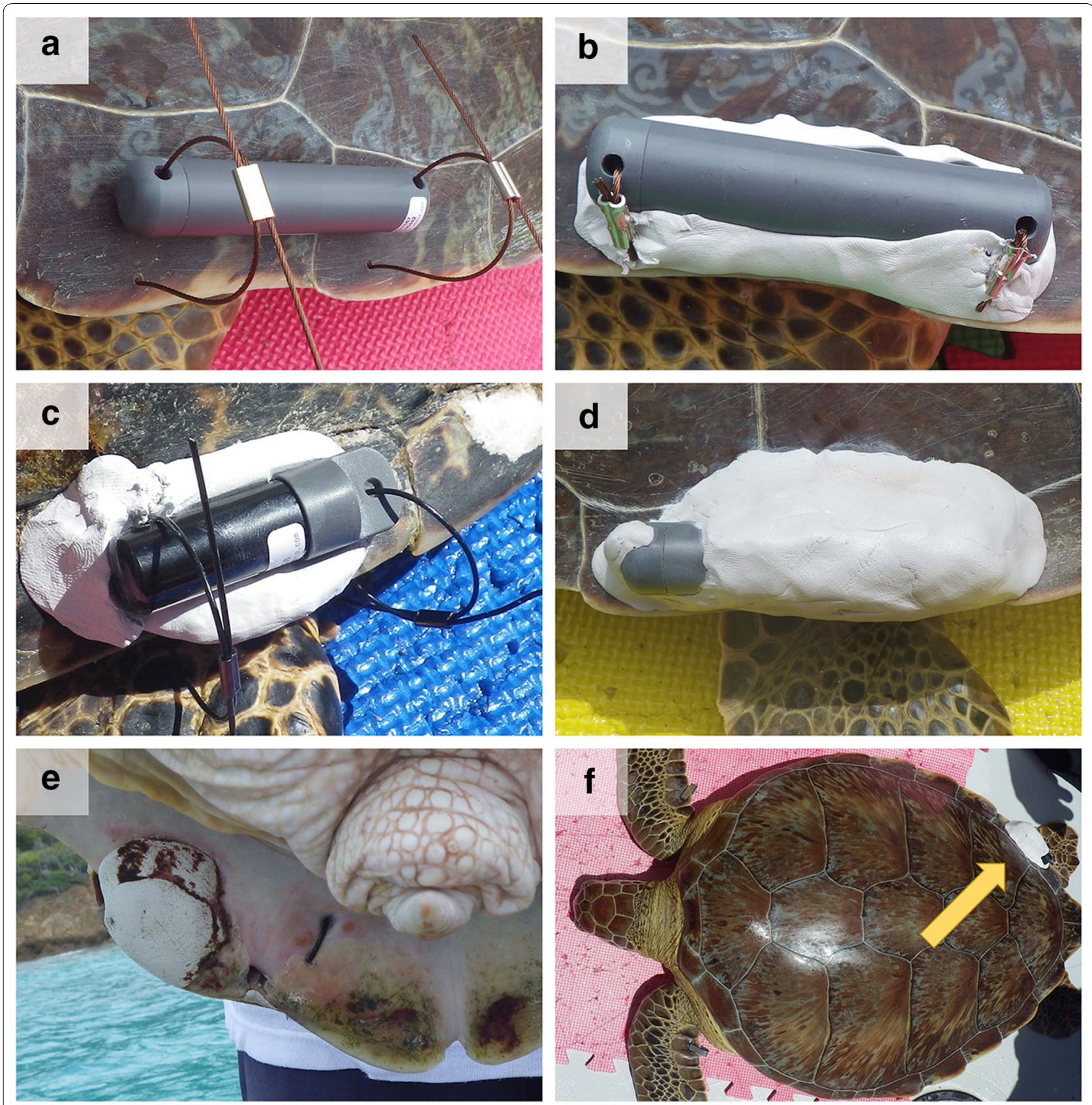

Fig. 1 Acoustic tag attachment method. Acoustic tags were attached to the flattest section of the posterior marginal scutes after being cleaned of epibionts using 80 grit sand paper and sterilized with $91 \%$ isopropyl alcohol. Two holes were drilled parallel to each other on either side of the positioned tag at the front (transmitting end) and back of the tag through which nylon-coated $1 \times 7$ stainless steel leader wire with $135 \mathrm{lb}$ test was run through (a). Devcon Marine Plastic Putty was mixed together and placed beneath the tag, after which the wire was drawn taught through two aluminum clamps that cinched shut, and excess wire was removed (b). Tags from the $\mathrm{V}$ - 16 family were typically attached using four holes (a, $\mathbf{b})$. Tags from the $V-13$ family were typically attached using only three holes (c). Finally, the remaining putty is placed around the tag with the transmitting end left open to not disrupt acoustic signal transmission (d). We wrapped some putty around the edge of the carapace and onto the bottom of the marginal scute (e). $\mathbf{f}$ Position of the tag on the turtle 
only three holes, two near the transmitting end and one lined up with the hole in the plastic end cap. In this case, we drilled the single hole $10-15 \mathrm{~mm}$ from the edge of the scute. We ran nylon-coated $1 \times 7$ stainless steel leader wire with $135 \mathrm{lb}$ test through the holes and attached aluminum sleeves loosely to the ends (Fig. 1a). We then mixed Devcon Marine Plastic Putty together and placed it beneath the tag. With the tag situated in place, we drew the wire taught through the two aluminum clamps and cinched them shut, and then, we removed the excess wire (Fig. 1b). Finally, we placed the remaining putty around the tag with the transmitting end left open to allow for unimpeded acoustic signal transmission (Fig. 1d). We wrapped some putty around the edge of the marginal to the bottom of the marginal scute (Fig. 1e). All turtles were kept beneath a clean towel cooled with seawater during the workup, observed for signs of any extraordinary distress, and released within an hour at the point of capture, in accordance with animal care protocols.

To estimate tag retention rates, we compiled data from recaptures of previously tagged individuals. Although array coverage was substantial at BIRNM, it was not sufficient to distinguish between tags that had been shed or a change in the turtle's movement pattern based on the detection data, so tag retention rates were determined using only the physical in-water capture events. Tag retention was thus a latent variable, and for any given tag, we do not know how long it remained attached. Instead, we treated tag retention across the study as a binomial process, and we analyzed tag retention rates using a generalized linear model (GLM, i.e., logistic regression). Our response variable was tag retention, represented by a 0 for no and 1 for yes. We built three models to test competing hypotheses about tag retention rates: (1) retention rate depended only on time; (2) retention rate depended on an interaction between time and species; and (3) tag retention was constant (i.e., a null model). All analyses were done in RStudio using $\mathrm{R}$ version 3.4.3 [23]. We fit the GLM using the function " $\operatorname{glm}()$ ", and we performed model selection using the function "model.sel()" from the package "MuMIn" [24]. We used corrected AIC (AICc) scores to rank models, and we evaluated goodness-of-fit using the pseudo- $R^{2}$ method of Nagelkerke [25]. After selecting a top model, we used it to predict and visualize tag retention rates for both species. To summarize our results, we reported the tag half-life, which is the average time after which $50 \%$ of the tags were still attached, as well as the $95 \%$ confidence interval for that estimate.

\section{Results}

We deployed 109 acoustic tags on 89 individual turtles between March 2012 and November 2017. We deployed 72 acoustic tags on 60 individual greens and 37 acoustic tags on 29 individual hawksbills. Of those tags, 67 were Vemco V16 tags (47 on greens and 20 on hawksbills), and 42 were Vemco V13 tags (25 on greens and 17 on hawksbills). Average juvenile hawksbill CCL-t at the initial tagging event was $47.5 \mathrm{~cm}(\mathrm{SD}=14.1 \mathrm{~cm})$. Average juvenile green CCL-t was $50.6 \mathrm{~cm}(\mathrm{SD}=10.3 \mathrm{~cm})$. In-water recapture rates over the course of the study were $41 \%$ for hawksbills (12 recaptures out of 29 total captures) and $68 \%$ for greens (41 recaptures out of 60 total captures). The average time between recaptures was 290 days for hawksbills and 425 days for greens. The maximum time a turtle was physically observed retaining a tag was 972 days for hawksbills and 181 days for greens. Many of the hawksbills in our study were last recaptured with their acoustic tag still attached, so this observed maximum would presumably increase with future sampling.

Our top model showed tag retention rate depended on an interaction between time and species. It received $100 \%$ of the model weight and outperformed the timeonly model by $\triangle \mathrm{AICc}=128.5$ (Table 1 ). Predictions from the top model show that tag half-life on greens was 150 days (95\% CI 116-188 days), and tag half-life on hawksbills was 1077 days (95\% CI 869-2118 days; Fig. 2). The estimated half-life on hawksbills was greater than the observed maximum retention time, because more than half of the hawksbills in our study still had their tags attached at the time of this analysis, and thus, the $95 \%$ confidence interval is very wide out past 1000 days (Fig. 2).

\section{Discussion}

Our observed tag retention rates have clear implications for study design and tag choice. We demonstrated a large difference in acoustic tag retention rate between juvenile green and hawksbill sea turtles at BIRNM, with average tag half-life estimated to be seven times as long for hawksbills as for greens. Thus, juvenile hawksbills can be tagged with acoustic tags for long-term studies using this method, whereas juvenile greens are likely to shed their tags in the 1st year, making long-term research difficult. Previous work investigating tag retention by marine turtles has focused either on identification tags (flipper

Table 1 Model selection table for the generalized linear model set describing tag retention rate

\begin{tabular}{llrrr}
\hline Model & Parameters & AICc & DAICc & Weight \\
\hline Time $\times$ species & 4 & 50.5 & 0.0 & 1.0 \\
Time & 2 & 179.0 & 128.5 & 0.0 \\
Null & 1 & 338.8 & 288.4 & 0.0 \\
\hline
\end{tabular}

We found strong support for the model containing an interaction of species with time over the time-only model. Both models strongly outperformed the null model 


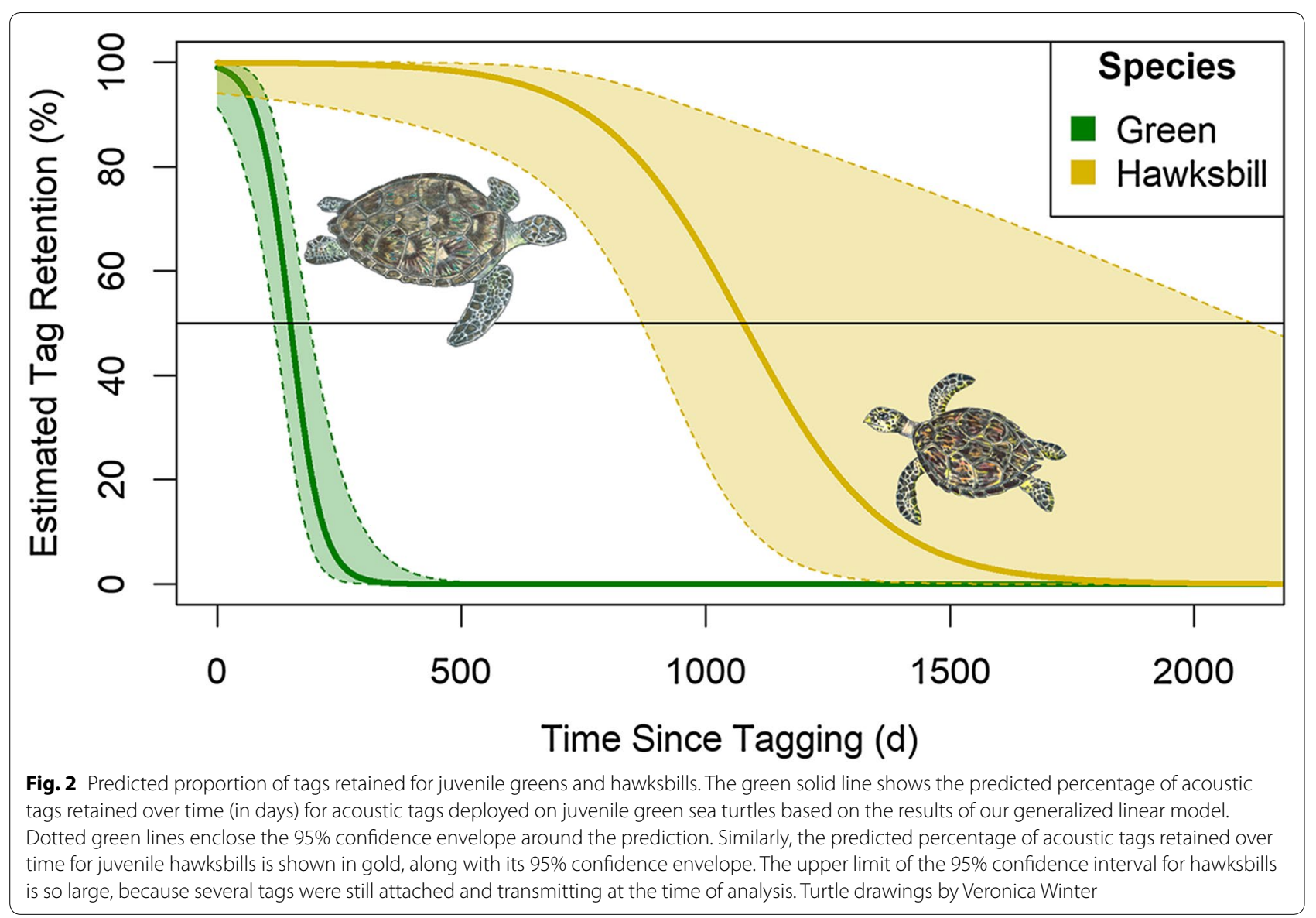

and internal PIT tags) for the purpose of capture-markrecapture studies or satellite and GPS tags $[6,9,26]$. Our study shows that tagging protocols should be speciesspecific, i.e., best practices are not necessarily the same for all hard-shelled turtles.

We observed that as the marginal scutes grew, the attachment holes moved closer to the edge of the scute and, particularly for greens, tended to enlarge in diameter due to wear. This wear pattern left holes near the edge of the scute prone to tear-out (Fig. 3). Tag retention was not the initial focus of our study, and we do not have detailed data to tease apart the reasons for this drastic difference in tag retention between the two species. We hypothesized that the difference could be due to (1) differences in behavior, (2) differences in growth rates, or (3) differences in the composition of the carapace. As for cause 1 , it seems that the difference is not likely due to behavior: hawksbills often wedge themselves in crevices of hard physical benthic structures such as reef and rock to rest and avoid predators, whereas greens typically remain in more open habitats such as sea grass pastures and low-density hardbottom [22, 27, 28]. These patterns would suggest that hawksbills should have a lower tag retention rate-the opposite pattern from what we observed. Cause 2 (differences in growth rate) does not seem to provide an obvious explanation, either. Studies in the region have found slightly greater growth rates for juvenile greens than for hawksbills [29, 30]; however, variability in somatic growth rates can be due to a number of different factors including cohort, population density, and quality of habitat. We calculated the annual change in straight carapace length to the notch (SCL-n) for recaptured individuals to be $3.3 \mathrm{~cm}(\mathrm{SD}=1.2 \mathrm{~cm})$ for greens and $3.5 \mathrm{~cm}(\mathrm{SD}=1.6 \mathrm{~cm})$ for hawksbills (THS, unpublished data). While these summary statistics might obscure differences in nonmonotonic growth, specifically at the tag attachment site on the posterior marginal scutes, the differences do not appear to be large enough to cause the observed difference in tag retention rates. Cause 3 (a difference in shell hardness), thus, seems to be the most likely explanation. Hawksbill shells are prized in the jewelry trade due in part to their physical traits and workability [31, 32]. We also observed frequent tearouts from green turtles (Fig. 3b, c), as their attachment holes wore closer to the edge of the marginal scutes, while hawksbill turtles did not tend to exhibit tear-outs 

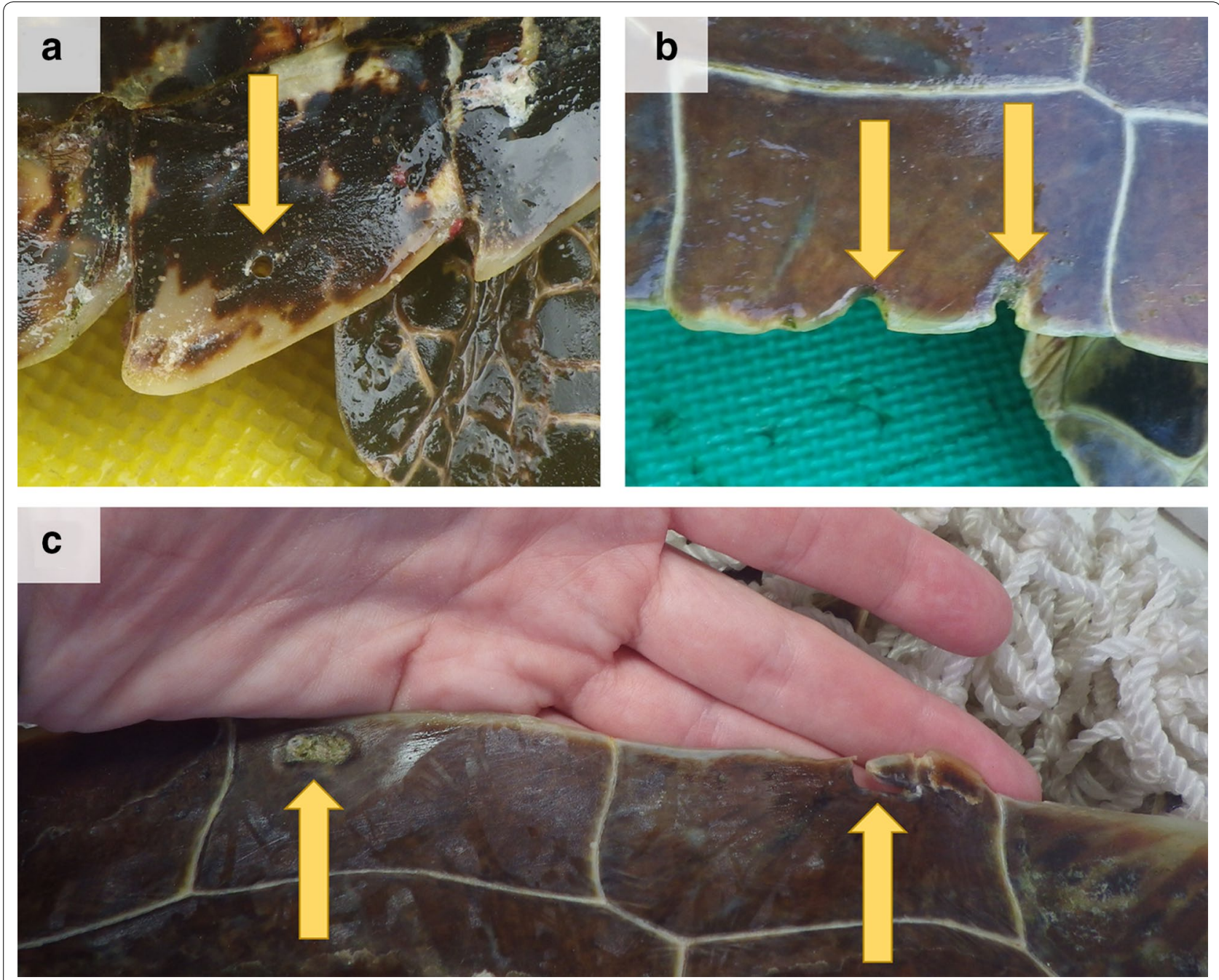

Fig. 3 Wear and growth of attachment holes on marginal scutes. All three panels show turtles recaptured after losing an acoustic tag, with arrows indicating the attachment holes. a Hawksbill turtle, whose attachment holes did not wear out or result in a tear-out. b Green turtle whose center attachment holes (for a V13 cap) moved out to the edge of the scute and wore out, resulting in a tear-out. c Green turtle whose inner attachment holes wore and moved to the edge, but only one of them (right) resulted in a tear-out, while the other remained intact

(Fig. 3a). We cannot rule out a combination of these factors, such as growth rates and carapace composition, but it is clear we have found a species-specific difference.

Our findings are, of course, specific to our tagging method. Since we have found that the holes tend to both wear and migrate towards the lateral edge of the marginal scutes, an attachment method that relies on drilling fewer holes (thus leaving more distance to the lateral edge) might result in longer tag retention in greens. For example, researchers working on both hard-shelled turtles (i.e., greens and loggerheads [Caretta caretta]) and leatherbacks (Dermochelys coriacea) have attached satellite transmitters via tether using just a single hole in the carapace, monofilament line, padded tubing, and buttons made of high-density plastic [33-35]. Alternatively, the placement of the tag towards the center of the carapace might also improve retention. Satellite and GPS tags are typically affixed to turtles using a two-part epoxy in the center of the carapace (although this tag placement puts the tag above the waterline when turtles surface; see, e.g., [36]).

Another important consideration when discussing acoustic tag retention rates is dealing with data from shed tags still in the array, often referred to as "ghost tags". Acoustic tags shed within range of receivers can drain receiver batteries more quickly (due to the increased workload of recording constant transmissions). Then, during data processing, more computing power is necessary to handle the sheer amount of detection data collected and discern the biologically relevant 
detections. As of December 2018, approximately 75\% of all detections of greens at BIRNM $(9,341,386$ total detections) were likely from shed tags (THS, personal observation). Our array, such as many others, features some overlapping receivers and has variable detection ranges [37], and therefore, small amounts of current and drift can result in a shed tag being detected at different nearby receivers over time-a pattern not immediately distinguishable from a slowly moving turtle or a turtle with a small home range. We have used a combination of visual inspection of detection data in conjunction with capture histories to manually determine probable dates a tag was lost, but when sifting through several million detections, this process quickly got out of hand. We suggest that more research into automated methods to identify shed tags still being detected in an array.

\section{Conclusions}

The tag attachment methods outlined here are clearly effective for long-term studies on juvenile hawksbills. However, our results highlight the need to explore other tag attachment techniques for juvenile greens if longterm detection histories are desired to achieve study objectives. This study is the first to identify the clear need for unique tagging protocols between species of hardshelled turtles. Further investigation into the reasons for the discrepancy in tag retention rates between these two species could also provide important insight into physiological, behavioral, or structural differences between these turtles. In the meantime, tag retention is an important consideration when designing a passive acoustic study for any species, and shed tags within the array remain an obstacle worth addressing in passive acoustic studies.

\begin{abstract}
Acknowledgements
Fieldwork was permitted under NMFS permits 16146 and 20315, National Park Service permits BUIS-2012-SCI-0002 and BUIS-2014-SCI-0009, USFWS permit TE38906B-0 issued to I. Lundgren, and Government of the Virgin Islands Department of Planning and Natural Resources scientific permit \#STX-02 issued to J. Tutein. We thank the NPS and USGS staff and volunteers Elissa Connolly-Randazzo, Eric Cusin, Andre Daniels, Scott Eanes, lan Lundgren, Devon Nemire-Pepe, Lee Richter, Ashley Ruffo, and Kevin Weng who were critical to the field portion of this study. We thank Veronica Winter for turtle drawings used in Fig. 2. Any use of trade, product, or firm names is for descriptive purposes only and does not imply endorsement by the U.S. Government.
\end{abstract}

\footnotetext{
Authors' contributions

All authors contributed to writing and editing the final manuscript. BJS assisted with the data processing, helped conduct the analysis, and created the figures. THS conducted fieldwork, refined the idea, and processed and analyzed the data. MSC conducted and supervised fieldwork. AGC conducted fieldwork and helped prepare the figures. ZHS contributed to study design and secured funding. CGP conducted and supervised fieldwork, provided logistical support, and supervised acoustic data downloads. KMH conceived the study, provided input on design, and secured funding. All authors read and approved the final manuscript.
}

Funding

Funding was through the USGS National Resource Preservation Program and an interagency agreement with NPS.

\section{Availability of data and materials}

The data analyzed in this paper are available from the USGS ScienceBase repository: https://doi.org/10.5066/P998D45N.

\section{Ethics approval and consent to participate}

Animal care protocols were approved through USGS IACUC permits USGSSESC2014-02, USGS-SESC-IACUC 2011-05, and USGS IACUC WARCIGNV 2017-04.

\section{Competing interests}

The authors declare that they have no competing interests.

\section{Author details}

${ }^{1}$ Cherokee Nation Technologies, Contracted to the U.S. Geological Survey, Davie, FL 33314, USA. ${ }^{2}$ U.S. Geological Survey, Wetland and Aquatic Research Center, Davie, FL 33314, USA. ${ }^{3}$ National Park Service, Buck Island Reef National Monument, Christiansted, St. Croix, Virgin Islands 008020-4611, USA.

Received: 14 February 2019 Accepted: 12 August 2019

Published online: 24 August 2019

\section{References}

1. Klimley AP. Why publish animal biotelemetry? Anim Biotelem. 2013;1:2-4.

2. Hussey NE, Kessel ST, Aarestrup K, Cooke SJ, Cowley PD, Fisk AT, et al. Aquatic animal telemetry: a panoramic window into the underwater world. Science (80-). 2015;348:1255642.

3. Hays GC, Bailey H, Bograd SJ, Bowen WD, Campagna C, Carmichael RH, et al. Translating marine animal tracking data into conservation policy and management. Trends Ecol Evol. 2019;34:459-73.

4. Hays GC, Ferreira LC, Sequeira AMM, Meekan MG, Duarte CM, Bailey H, et al. Key questions in marine megafauna movement ecology. Trends Ecol Evol. 2016;31:463-75.

5. Cooke SJ, Hinch SG, Wikelski M, Andrews RD, Kuchel L, Wolcott TG, et al. Biotelemetry: a mechanistic approach to ecology. Trends Ecol Evol. 2004;19:334-43. https://doi.org/10.1016/j.tree.2004.04.003.

6. Jones TT, Van Houtan KS, Bostrom BL, Ostafichuk P, Mikkelsen J, Tezcan E, et al. Calculating the ecological impacts of animal-borne instruments on aquatic organisms. Methods Ecol Evol. 2013;4:1178-86.

7. Mansfield KL, Wyneken J, Rittschof D, Walsh M, Lim CW, Richards PM. Satellite tag attachment methods for tracking neonate sea turtles. Mar Ecol Prog Ser. 2012;457:181-92.

8. Jepsen N, Thorstad EB, Havn T, Lucas MC. The use of external electronic tags on fish: an evaluation of tag retention and tagging effects. Anim Biotelem. 2015;3:49

9. Venerus LA, Irigoyen AJ, Parma AM. Assessment of biases in the estimation of tag shedding rates through a mark-resight experiment. Fish Res. 2013;140:133-48

10. Godley BJ, Blumenthal JM, Broderick AC, Coyne MS, Godfrey MH, Hawkes $L A$, et al. Satellite tracking of sea turtles: where have we been and where do we go next? Endanger Species Res. 2008;4:3-22.

11. Rutz C, Hays GC. New frontiers in biologging science. Biol Lett. 2009;5:289-92. https://doi.org/10.1098/rsbl.2009.0089.

12. Seminoff JA, Shanker K. Marine turtles and IUCN Red Listing: a review of the process, the pitfalls, and novel assessment approaches. J Exp Mar Biol Ecol. 2008;356:52-68.

13. Dizon $A E$, Balazs $G H$. Radio telemetry of Hawaiin green turtles at their breeding colony. Mar Fish Rev. 1982;44:13-20.

14. Schofield G, Bishop CM, MacLean G, Brown P, Baker M, Katselidis KA, et al. Novel GPS tracking of sea turtles as a tool for conservation management. J Exp Mar Biol Ecol. 2007;347:58-68. https://doi.org/10.1016/j.jembe .2007.03.009.

15. Fossette S, Schofield G, Lilley MKS, Gleiss AC, Hays GC. Acceleration data reveal the energy management strategy of a marine ectotherm during reproduction. Funct Ecol. 2012;26:324-33. 
16. Heupel MR, Semmens JM, Hobday AJ. Automated acoustic tracking of aquatic animals: scales, design and deployment of listening station arrays. Mar Freshw Res. 2006;57:1-13.

17. Udyawer V, Dwyer RG, Hoenner X, Babcock RC, Brodie S, Campbell HA, et al. A standardised framework for analysing animal detections from automated tracking arrays. Anim Biotelem. 2018;6:1-14. https://doi. org/10.1186/s40317-018-0162-2

18. Musick JA, Limpus CJ. Habitat utilization and migration in juvenile sea turtles. In: Lutz PL, Musick JA, editors. The biology of sea turtles. Boca Raton: CRC Press; 1997. p. 137-64.

19. Carr A, Hirth H, Ogren L. Ecology and migrations of sea turtles, 6 : the hawksbill turtle in the Caribbean Sea. Am Museum Novit. 1964;2248:1-29.

20. Taquet $C$, Taquet M, Dempster T, Soria M, Ciccione S, Roos D, et al. Foraging of the green sea turtle Chelonia mydas on seagrass beds at Mayotte Island (Indian Ocean), determined by acoustic transmitters. Mar Ecol Prog Ser. 2006;306:295-302.

21. Hazel J, Hamann M, Lawler IR. Home range of immature green turtles tracked at an offshore tropical reef using automated passive acoustic technology. Mar Biol. 2013;160:617-27.

22. Blumenthal JM, Austin TJ, Bothwell JB, Broderick AC, Ebanks-Petrie G, Olynik JR, et al. Diving behavior and movements of juvenile hawksbill turtles Eretmochelys imbricata on a Caribbean coral reef. Coral Reefs. 2009;28:55-65.

23. R Core Team. R: a language and environment for statistical computing. Vienna: R Foundation for Statistical Computing; 2017.

24. Barton K. MuMIn: multi-model inference. R Package version 1.40.4. 2018 https://cran.r-project.org/package=MuMln.

25. Nagelkerke NJD. A note on a general definition of the coefficient of determination. Biometrika. 1991;78:691-2.

26. Rivalan P, Godfrey MH, Girondot M. Maximum likelihood estimates of tag loss in leatherback sea turtles. J Wildl Manag. 2000;69:540-8.

27. Wood LD, Brunnick B, Milton SL. Home range and movement patterns of subadult hawksbill sea turtles in Southeast Florida. J Herpetol. 2017;51:58-67.

28. Chevis MG, Godley BJ, Lewis JP, Lewis JJ, Scales KL, Graham RT. Movement patterns of juvenile hawksbill turtles Eretmochelys imbricata at a Caribbean coral atoll: long-term tracking using passive acoustic telemetry. Endanger Species Res. 2017;32:309-19.
29. Labrada-Martagón V, Muñoz Tenería FA, Herrera-Pavón R, NegretePhilippe A. Somatic growth rates of immature green turtles Chelonia mydas inhabiting the foraging ground Akumal Bay in the Mexican Caribbean Sea. J Exp Mar Biol Ecol. 2017;487:68-78.

30. Krueger B, Chaloupka M, Leighton P, Dunn J, Horrocks J. Somatic growth rates for a hawksbill turtle population in coral reef habitat around Barbados. Mar Ecol Prog Ser. 2011;432:269-76.

31. Parsons JJ. The hawksbill turtle and the tortoise shell trade. In: Études de géographie tropicale offertes a Pierre Gourou. Paris: Mouton; 1972. p. 45-60.

32. Shattuck EF. Geographic origins of illegally harvested hawksbill sea turtle. Michigan: Michigan State University; 2011.

33. Patel SH, Panagopoulou A, Morreale SJ, Kilham SS, Karakassis I, Riggall T, et al. Differences in size and reproductive output of loggerhead turtles Caretta caretta nesting in the eastern Mediterranean Sea are linked to foraging site. Mar Ecol Prog Ser. 2015;535:231-41.

34. Blanco GS, Morreale SJ, Bailey H, Seminoff JA, Paladino FV, Spotila JR. Postnesting movements and feeding grounds of a resident East Pacific green turtle Chelonia mydas population from Costa Rica. Endanger Species Res. 2012;18:233-45.

35. Robinson NJ, Morreale SJ, Nel R, Paladino FV. Coastal leatherback turtles reveal conservation hotspot. Sci Rep. 2016;6:1-9. https://doi.org/10.1038/ srep37851.

36. Hart KM, Zawada DG, Fujisaki I, Lidz BH. Internesting habitat-use patterns of loggerhead sea turtles: enhancing satellite tracking with benthic mapping. Aquat Biol. 2010;11:77-90.

37. Selby TH, Hart KM, Fujisaki I, Smith BJ, Pollock CJ, Hillis-Starr Z, et al. Can you hear me now? Range-testing a submerged passive acoustic receiver array in a Caribbean coral reef habitat. Ecol Evol. 2016;6:4823-35. https:// doi.org/10.1002/ece3.2228.

\section{Publisher's Note}

Springer Nature remains neutral with regard to jurisdictional claims in published maps and institutional affiliations.
Ready to submit your research? Choose BMC and benefit from:

- fast, convenient online submission

- thorough peer review by experienced researchers in your field

- rapid publication on acceptance

- support for research data, including large and complex data types

- gold Open Access which fosters wider collaboration and increased citations

- maximum visibility for your research: over 100M website views per year

At BMC, research is always in progress.

Learn more biomedcentral.com/submissions 